\title{
1 Effect of microwave treatment on physicochemical properties of maize flour
}

2 Laura Román ${ }^{1}$, Mario M. Martínez ${ }^{1}$, Cristina M. Rosell ${ }^{2}$, Manuel Gómez ${ }^{1}$ *

$3 \quad{ }^{1}$ Food Technology Area.

4 College of Agricultural Engineering, University of Valladolid, 34004 Palencia, Spain

5 Tel: +34 979-108495 fax +34 979-108302

$6{ }^{2}$ Institute of Agrochemistry and Food Technology (IATA-CSIC). Avda Agustin Escardino, 7.

7 Paterna-46980, Spain.

$8 \quad{ }^{*}$ Corresponding author e-mail: pallares@iaf.uva.es

\section{Abstract}

Relatively little work has been reported about flour changes during microwave irradiation. For this 11 reason, maize flours were treated by microwave radiation at $400 \mathrm{~W}$ for $0.5,1,2$ and 4 minutes, and their microstructure and physicochemical characteristics (X-ray diffractometry, differential scanning calorimetry and pasting properties) were analysed. Micrographs showed that maize flour treated by microwave radiation displayed less compacted particles and more swollen starch granules. Treated maize flours displayed higher V-type crystalline structure, indicating amylose-lipid complexes formation. Additionally, onset and peak temperature and gelatinization enthalpy increased when increasing treatment time of samples. Maize flours subjected to mild treatment ( 0.5 and 1 minute) showed higher peak viscosity and breakdown than native maize flour, and maize samples subjected to severe treatments ( 2 and 4 minutes) displayed a lower peak viscosity and breakdown, which reflects an increase in shear stability, respect to native maize sample. In general, microwave treatment fostered changes in starch crystallinity and the formation of amylose-lipid complexes affecting the functional properties of flour such as its pasting behaviour and its thermal properties. 


\section{Introduction}

27 Maize is the main produced cereal (tonnes) followed by paddy rice and wheat (FAOSTAT 2013). Maize kernels are submitted to different treatment depending on the final product. Grit and meal maize are used in the production of snacks and breakfast cereals, whereas maize flour is mostly used in blends with wheat flours in bakery products. In America, maize is used to make various Latin products like arepas, hallacas, empanadas and pasabocas, but the main consumption is nixtamalized to produce other products such as tortillas, tamales or snacks (Pineda-Gómez et al. 2012). In some of these foods, hydrothermal treated flours (instant flours) are very useful to simplify the production (less time and energy) (ReyesMoreno et al. 2003; Zeppa et al. 2012).

Physical hydrothermal processes allow modifying the functional properties of the flours for being used in food processing. During hydrothermal treatments, the starch is subjected to high moisture and temperature. Depending on the intensity of the treatment, starch might be gelatinized, broken the structure of granules, increased the swelling power of the granule, and lost the crystallinity (Atwell et al. 1988). Different thermal treatments for producing instant flours have been proposed as drum drying (Anastasiades et al. 2002; Valous et al. 2002), dry heat treatment (Johnson et al. 1980), extrusion (Meshram et al. 2009; Reyes-Moreno et al. 2003) and microwave heating (Martínez-Bustos et al. 2000). Microwaves are electromagnetic waves in the frequency range of 300-300,000 MHz. Polar molecules absorb microwave energy and orient themselves with respect to the electric field. The rapid change in their orientation generates heat by molecular friction (Sumnu 2001), resulting in a bulk heating throughout the sample and a faster heating rate compared with the conventional heating. There has been a big interest in the industrial application of microwaves to improve conventional processes (Luo et al. 2006). Thus, the effects of microwave treatment on the chemical and physicochemical properties of cereal starches have been reported. Fan et al. (2012) reported that microwave irradiation had no effect on the optical and thermal properties of rice starch during gelatinization respect conventional heating. Lewandowicz et al. (2000) found an increase in gelatinization temperature and a decrease in solubility of 51 microwaved maize and wheat starches. Stevenson et al. (2005) also reported an increase of gelatinization 
temperature and decrease of paste viscosity of microwaved maize starch. Anderson and Guraya (2006) and Luo et al. (2006) investigated, respectively, the effect of microwave on rice and maize starches with different proportion of amylose/amylopectin. Rearrangements of the molecular structure during microwave heating produced significant changes in viscosity properties of both waxy and non-waxy starches. Furthermore, Pinkrová et al. (2003) reported that the peak viscosity of rice flour decreased as temperature and microwave power level applied to rice grain increased.

Therefore, the effect of microwave heating has been focused on starches. Nevertheless, flours, as compared to starches, have a higher nutritional value and the extraction process is more economical with a lower environmental impact (Eckhoff and Watson 2009). However, relatively little work has been reported on flour changes during microwave irradiation, solely on wheat (Ashraf et al. 2012). Sun et al. (2014) applied heat moisture treatment to sorghum starch and flour, demonstrating physicochemical differences between both. The treatment had a far greater effect on solubility, swelling power, setback viscosity, enthalpy of gelatinization and crystallinity of flour than that of starch. Consequently, although studies on maize starch have been previously reported (Lewandowicz et al. 2000; Stevenson et al. 2005), it is necessary to study the effect of microwave on maize flours.

The aim of the present research was to evaluate the effect of microwave radiation (0.5, 1, 2 and 4 min) to moistened $(30 \%)$ maize flours on the crystallinity, gelatinization parameters, retrogradation characteristics, hydration and pasting properties.

\section{Materials and methods}

\subsection{Materials}

Maize flour was procured from Adpan Europe S.L. (Asturias, Spain), with a moisture content of 11.95\%, $7.6 \mathrm{~g}$ of proteins and $3 \mathrm{~g}$ of lipids per $100 \mathrm{~g}$ of sample (Data were provided by the manufacturer).

\subsection{Methods}

\subsubsection{Microwave irradiation of flour samples}


Maize flours were heated in a microwave oven Kompernass GMBH, Silver Crest SMW 800 A2 (Bochum, Germany). Previously, flour tempering to $30 \%$ moisture content was carried out in a mixer MR-2L Chopin (Villeneuve-la-Garenne, France) for one hour by adding the appropriate amount of water up to $30 \%$ moisture content according to the initial moisture of the flour. Then, samples were allowed to stand 24 hours at room temperature in order to equilibrate the moisture content. Microwave oven was preheated to achieve a standard uniform temperature, by heating $200 \mathrm{~mL}$ of distilled water for $0.5 \mathrm{~min}$, before each treatment. Samples (100.0 g each) were treated at 400W (intermediate continuous power) in an open cylindrical glass plate (diameter: $150 \mathrm{~mm}$, height: $75 \mathrm{~mm}$ ) for 0.5, 1, 2 and $4 \mathrm{~min}$. Samples were left into the oven for one additional minute till cooling down and later were adequately homogenized with a glass rod. After microwave treatment, flours were sieved on an automatically Buhler sieving model MLI300B (Uzwil, Switzerland), through a 132 mesh screen, to remove particle clumps. Particle clumps were present in all cases in amounts lower than $10 \%$ of the weight of flour. Those clumps were milled using a Perten instruments laboratory mill 3303 (Huddinge, Sweden) and reincorporated to the rest of the flour. Flours were stored in air-tight plastic containers and held at $4^{\circ} \mathrm{C}$ until further analyses. Two sets of samples were carried out for each treatment. Moisture content of the flour was analyzed in duplicate according to the method 44-16.01 (AACCI, 2012).

\subsubsection{Microscopic observations}

Flour photomicrographs were taken with Quanta 200FEI (Hillsboro, Oregon, USA) environmental scanning electron microscope (ESEM). Photomicrographs were taken in beam deceleration mode (BDM) at $1.5 \mathrm{KeV}$ in high vacuum mode with a backscattered electron detector (BSED).

\subsubsection{X-ray diffraction (XRD)}

Samples were analyzed using a Bruker D8 Discover A25 (Bruker AXS, Rheinfelden, Germany) equipped with a copper tube operating at $40 \mathrm{kV}$ and $40 \mathrm{~mA}$, producing CuKa radiation of $0.154 \mathrm{~nm}$ wavelength. Diffractograms were obtained by scanning from $5^{\circ}$ to $40^{\circ}$ (2theta) at a rate of $1.2 \%$ min, a step size of 
$1000.02^{\circ}$, a divergence slit width variable (DS) of $5 \mathrm{~mm}$ and a scatter slit width (SS) of $2.92^{\circ}$, and a nickel

101 filter 0.02 to exclude $K \beta$ radiation.

\section{$102 \quad$ 2.2.4 Differential scanning calorimetry (DSC)}

103 Analyses were performed in a differential scanning calorimeter DSC-7 (Perkin-Elmer, Waltham, MA, 104 USA) as reported Martínez et al. (2014). Thermal transitions of samples for gelatinization were 105 characterized by onset temperature (To), peak temperature (Tp), gelatinization temperature range (Tp$106 \mathrm{To}$ ) as well as the enthalpy of starch gelatinization $(\Delta \mathrm{Hg})$ (expressed as $\mathrm{mJ} / \mathrm{mg}$ of sample). The enthalpy 107 calculations were based on dry-flour weight. All samples were run in triplicate.

\subsubsection{Pasting properties}

109 Pasting properties of flours were analyzed using the standard method 61-02.01 (AACCI, 2012), with a 110 Rapid Visco Analyser (RVA-4) controlled by Thermocline software (Newport Scientific Pty. Limited, 111 Warriewood, Australia) for Windows. At least two RVA profiles were obtained for each sample.

\section{$112 \quad$ 2.2.6 Statistical analysis}

113 Simple analyses of variance were used to determine the effects of microwave treatment. Fisher's least 114 significant difference (LSD) test was used to describe means with 95\% confidence. Statgraphics 115 Centurion XVI (Statpoint Technologies, Warrenton, USA) was used as statistical analysis software.

\section{3. Results and Discussion}

\section{$117 \quad 3.1$ Microscopic observations}

118 Fig. 1 shows that microwaved flours ( $b$ and $c)$ showed a more disaggregated structure (white arrows)

119 than the native one (black arrow). It was also observed that these flours lose gradually the compact 120 matrix where starch granules were integrated into the protein; instead starch granules showed more naked 121 and slightly swollen structure. This effect increased with the time of treatment. The swelling of the starch 122 granules in treated flours might be due to the modest structural reorganizations (annealing) occurred 123 during microwave treatment owing to in the excess of water at temperatures above the glass transition 124 temperature (Biliaderis 2009). In addition, no breakage of the starch granules was observed, indicating 
that starch gelatinization was not complete, thus either the temperature or the time of treatment was not enough to produce starch gelatinization.

127 Luo et al. (2006) also observed changes on starch granule structure when moistened (30\%) starch maize

128 were treated $20 \mathrm{~min}$ in microwave at $1 \mathrm{~W} / \mathrm{g}$. Nevertheless, they observed some breakage, cracks and 129 porous on the surface of the starch granules. Those observations were attributed to possible transfers and 130 internal rearrangements of the particles. Likely, the shorter time, and thus power, employed in the flour 131 treatments of the present study were not sufficient to visibly damage the starch granules.

\section{$132 \quad 3.2$ X-ray diffraction}

133 The crystalline structures of maize flours were studied using XRD. The diffractograms (Fig. 2) showed 134 that all samples maintained A-type crystallinity, typical of cereal starches, after microwave treatment. 135 Nevertheless, microwave treatment had a strong influence on their crystalline order, increasing the 136 intensity of the peaks and maintaining d-spacing, which agrees with Luo et al. (2006). These findings 137 could indicate a crystalline growth fostered by microwave treatment. Starch granules, being partially 138 crystalline entities, are prone to molecular reorganization (annealing) when held in excess of water at 139 temperatures above the glass transition temperature and below the equilibrium temperature of the 140 crystallites. Softening of the amorphous granular regions enables crystalline growth and/or perfection

141 (Biliaderis 2009). Microwave treatment of maize flours also led to a V-type crystalline peaks formation 142 at $2 \theta$ of around $20^{\circ}$ (arrow mark). Lopez-Rubio et al. (2008) affirmed that V-type crystalline structure 143 can be originated from single helical amylose, such as amylose-lipid complexes. In a single-helical 144 complex, the linear portion of the starch molecule has its hydrophobic side of the molecule facing the 145 cavity of the helix and interacting with the non-polar moiety of the complexing agent, such as fatty acids 146 (Jane, 2009).

\section{$147 \quad 3.3$ Differential scanning calorimetry (DSC)}

148 The influence of microwave treatment on thermal properties of maize flours is presented in Table 1. In 149 the range of temperature tested, flours exhibited one endothermic peak, corresponding to amylopectin 
gelatinization. Microwave treatment affect the gelatinization temperatures of maize flours since their

151 onset and peak temperatures shifted to higher temperatures. Chiu and Solarek (2009) reported that after

152 hydrothermal treatments the starch gelatinization temperature was higher, the gelatinization endotherm

153 more defined and the energy of gelatinization increased, coinciding with the results of this study. When

154 crystallites perfection is higher, greater gelatinization temperatures are required to melt starch crystallites

155 (Ji et al. 2004). Therefore, the increase of gelatinization temperature observed in moistened treated flours

156 would be in agreement with XRD results. The rise in gelatinization temperatures has also been associated

157 with the formation of amylose-amylose and amylose-lipid complexes within the starch granule

158 (Lewandowicz et al. 2000; Sun et al. 2014). Lewandowicz et al. (2000) also suggested that higher

159 gelatinisation temperature of microwaved starches may indicate an association and a more stable

160 configuration in a granular structure. The present study shows that these associations could be effective

161 after certain time of treatment (1-2 $\mathrm{min})$. Meanwhile, the range of temperature where gelatinization

162 proceeds was narrowed in flours subjected to microwave treatment. Differences observed in Tc-To

163 suggest that microwave irradiation leads to the formation of more stable and homogeneous crystallites.

164 Compared to native maize flour, gelatinization enthalpy increased in microwaved maize flours.This

165 observation is in accordance to Biliaderis (2009), who highlighted a same trend in other hydrothermal

166 treatments carried out in excess of water at temperatures below gelatinization temperature. Conversely,

167 some other researchers reported a significant decrease in the enthalpy when maize starches were

168 subjected to microwave irradiation (Lewandowicz et al. 2000; Luo et al. 2006; Stevenson et al. 2005).

169 These differences could be due to the fact that in these studies, longer microwave treatment of maize

170 starch was applied, between 20-60 min. This excessive treatment could cause the reduction of

171 crystallinity, as a consequence of the partial starch gelatinization (Sun et al. 2014).

\section{$172 \quad 3.4$ Pasting properties}

173 Pasting profiles of native maize flour and microwaved treated flours are plotted in Fig. 3. Treated

174 samples showed an increase in viscosity during the heating-cooling cycle when very short time of 175 microwave treatments was applied ( $0.5 \mathrm{~min}$ and $1 \mathrm{~min})$. But longer treatment times induced the opposite 
effect and a decrease in the viscosity was observed. The decrease of the maximum viscosity was also observed by Pinkrová et al. (2003) when increasing temperature of microwave treatment of rice grain and increasing power output at moisture content of $30 \%$. Luo et al. (2006) related this reduction of peak viscosity with an increment of inter- and intra-molecular hydrogen bonding due to association of starch

180 chains during microwave treatment.

181 Pasting temperatures of maize flour increased as longer treatments were applied, similarly to what was observed with gelatinization temperatures in the DSC analysis, indicating that flour might have greater difficulty to absorb water and start swelling. Higher crystallinity and rigidity of the starch granules

184 impede water absorption; in fact, the increased crystallinity promotes a delay in the gelatinization onset, since water is principally absorbed by amorphous regions (Sun et al. 2014). Hence, this rise in the pasting temperature agrees with the major crystallinity found in XRD analysis of treated flours. Moreover, Jane et al. (1999) reported the association between higher pasting temperature and the formation of amylose-

188 lipid complexes, which in fact were envisaged in the XRD analysis of moistened treated flour. In consequence, microwave treatment of flours in the presence of sufficient water induced the formation of amylose-lipid complexes besides an increase in crystallinity, which led to a delay in the gelatinization and pasting temperature. Moreover, other components of maize flour, such as proteins could have interacted with starch after microwave treatment increasing the pasting temperature and retarding gelatinization. In fact, Sun et al. (2014) studying heat moisture treatment found a higher pasting

194 temperature of sorghum flour as compared to starch, which they attributed to protein effect. The breakdown viscosity also decreased with longer microwave treatment of flours, which reflects an

196 increase in shear stability of microwave heat-treated flour (Anderson and Guraya 2006; Sun et al. 2014).

197 The increasing stability may be due to the formation of amylose-lipid complexes (Rumroytum et al.

198 2014) as a result of the stiffer starch granules and the presence of rigid non-fragmented swollen granules.

199 The tendency observed in setback is the one seen for the peak viscosity, resulting in a more elevated final

200 viscosity at the two shorter times. The reduction of final viscosity would be due to the formation of 201 amylose-lipid complexes, because amylose chains would not be any more available for recrystallization. 


\section{Conclusion}

203 Microwave treatments in which flours have enough water content are likely to modify the crystallinity of

204 their starch granules, promoting a swelling and amylose-lipid complexes formation, without causing 205 starch gelatinization. Furthermore, shear stability of these flours is improved while setback is cut down. 206 Therefore, microwave treatment could be used to obtain modified maize flours more suitable for some 207 food applications.

\section{Acknowledgements}

209 This study was supported financially by Junta de Castilla y León (VA054A12-2), Spain. The authors are 210 also grateful to Spanish Education Ministry for the research fellowship of Laura Román. Mario M.

211 Martínez would like to thank predoctoral fellowship from University of Valladolid.

\section{References}

213 AACC International (2012). Approved methods of analysis. St. Paul, Minnesota: AACC International.

214 Anastasiades, A., Thanou, S., Loulis, D., Stapatoris, A., \& Karapantsios, T.D. (2002). Rheological and 215 physical characterization of pregelatinized maize starches. Journal of Food Engineering, 52, 57-66.

216 Anderson, A. K., \& Guraya, H. S. (2006). Effects of microwave heat-moisture treatment on properties of 217 waxy and non-waxy rice starches. Food Chemistry, 97, 318-323.

218 Ashraf, S., Saeed, S. M. G., Sayeed, S. A., \& Ali, R. (2012). Impact of microwave treatment on the 219 functionality of cereals and legumes. International Journal of Agriculture and Biology, 14, 356-370.

220 Atwell, W., Hood, L., Lineback, D., Varriano Marston, E., \& Zobel, H. (1988). The terminology and 221 methodology associated and basic starch phenomena. Cereal Foods World, 33, 306-311.

222 Biliaderis, C. G. (2009). Structural transitions and related physical properties of starch. In J. BeMiller \& 223 R. Whistler (Eds.), Starch. Chemistry and Technology, (pp. 293-372). New York: Academic Press.

224 Chiu, C., \& Solarek, D. (2009). Modification of starches. In J. BeMiller \& R. Whistler (Eds.), Starch. Chemistry and Technology, (pp. 629-648). New York: Academic Press. 
Eckhoff, S. R., \& Watson, S. A. (2009). Corn and sorghum starches: Production. In J. BeMiller \& R.

227 Whistler (Eds.), Starch. Chemistry and Technology, (pp. 373-440). New York: Academic Press.

228 Fan, D., Ma, S., Wang, L., Zhao, J., Zhang, H., \& Chen, W. (2012). Effect of microwave heating on optical and thermal properties of rice starch. Starch/Stärke, 64, 740-744.

230 FAOSTAT (2013). Database of Food and Agricultural Organization. Available from 231 http://faostat3.fao.org/compare/E Accessed January 2015.

232 Jane, J. (2009). Structural features of starch granules II. In J. BeMiller, \& R. Whistler, (Eds.), Starch. Chemistry and Technology (pp. 193-236). New York: Academic Press.

234 Jane, J., Chen, Y. Y., Lee, L. F., Mcpherson, A. E., Wong, K. S., Radosavljevic, M., \& Kasemsuwan, T. 235 (1999). Effects of amylopectin branch chain length and amylose content on the gelatinization and pasting 236 properties of starch. Cereal Chemistry, 76, 629-637.

237 Ji, Y., Ao, Z., Han, J. A., Jane, J. L., \& BeMiller, J. N. (2004). Waxy maize starch subpopulations with 238 different gelatinization temperatures. Carbohydrate Polymers, 57, 177-190.

239 Johnson, B. A., Rooney, L. W., \& Khan, M. N. (1980). Tortillas making characteristics of micronized 240 sorghum and corn flours. Journal of Food Science, 45, 671-674.

241 Lewandowicz, G., Jankowskib, T., \& Fornal, J. (2000). Effect of microwave radiation on 242 physicochemical properties and structure of cereal starches. Carbohydrate Polymers, 42, 193-199.

243 Lopez-Rubio, A., Flanagan, B., Gilbert, E., \& Gidley, M. (2008). A novel approach for calculating starch 244 crystallinity and its correlation with double helix content: A combined XRD and NMR study. 245 Biopolymers, 89, 761-768.

246 Luo, Z., He, X., Fu, X., Luo, F., \& Gao, Q. (2006). Effect of microwave radiation on the 247 physicochemical properties of normal corn, waxy corn and amylomaize V starches. Starch/Stärke, 58, $468-474$. 
Martínez, M. M., Calviño, A., Rosell, C. M., \& Gómez, M. (2014). Effect of different extrusion 250 treatments and particle size distribution on the physico-chemical properties of rice flour. Food and 251 Bioprocess Technology, 7, 2657-2665.

252 Martínez-Bustos, F., García, M. N., Chang, Y. K., Sánchez-Sinencio, F., \& Figueroa, J. D. C. (2000). 253 Characteristics of nixtamalized maize flours produced with the use of microwave heating during alkaline 254 cooking. Journal of the Science of Food and Agriculture, 80, 651-656.

255 Meshram, M. W., Patil, V. V., Waje, S. S., \& Thorat, B. N. (2009). Simultaneous gelatinization and 256 drying of maize starch in a single-screw extruder. Drying Technology, 27, 113-122.

257 Pineda-Gómez, P., Acosta-Osorio, A. A., Cora, D. F., Rosales-Rivera, A., Sánchez-Echéverri, L. A., 258 Rojas-Molina, I., \& Rodríguez-García, M. E. (2012). Physicochemical characterization of traditional and 259 commercial instant corn flours prepared with threshed white corn. CyTA- Journal of Food, 10, 287-295.

260 Pinkrová, J., Hubáčková, B., Kadlec, P., Př́ihoda, J., \& Bubník, Z. (2003). Changes of starch during 261 microwave treatment of rice. Czech Journal of Food Sciences, 21, 176-184.

262 Reyes-Moreno, C., Milán-Carrillo, J., Gutierrez-Dorado, R., Paredes-Lopez, O., Cuevas-Rodríguez, E. 263 O., \& Garzón-Tiznado, J. A. (2003). Instant flour from quality protein maize (zea mays L). Optimization 264 of extrusion process. LWT-Food Science and Technology, 36, 685-695.

265 Rumroytum, P., Borompichaichartkul, C., \& Kongpensuk, V. (2014). Effect of drying involving 266 fluidisation in superheated steam on physicochemical and antioxidant properties of thai native rice 267 cultivars. Journal of Food Engineering, 123, 143-147.

268 Stevenson, D. G., Biswas, A., \& Inglett, G. E. (2005). Thermal and pasting properties of microwaved 269 corn starch. Starch/Stärke, 57, 347-353.

270 Sumnu, G. (2001). A review on microwave baking of foods. International Journal of Food Science and 271 Technology, 36, 117-127.

272 Sun, Q., Han, Z., Wang, L., \& Xiong, L. (2014). Physicochemical differences between sorghum starch 273 and sorghum flour modified by heat-moisture treatment. Food Chemistry, 145, 756-764. 
274 Valous, N. A., Gavrielidou, M. A., Karapantsios, T. D., \& Kostoglou, M. (2002). Performance of a 275 double drum dryer for producing pregelatinized maize starch. Journal of Food Engineering, 51, 171-183. 276 Zeppa, G., Bertolino, M., \& Rolle, L. (2012). Quantitative descriptive analysis of Italian polenta 277 produced with different corn cultivars. Journal of the Science of Food and Agriculture, 92, 412-417.

\section{Tables}

279 Table 1. DSC characteristics of native and microwave treated flours.

\begin{tabular}{lcccccc}
\hline Type & $\begin{array}{c}\text { Time of } \\
\text { treatment }(\mathbf{m i n})\end{array}$ & $\begin{array}{c}\mathbf{T}_{\mathbf{0}} \\
\left({ }^{\circ} \mathbf{C}\right)\end{array}$ & $\begin{array}{c}\mathbf{T}_{\mathbf{p}} \\
\left({ }^{\circ} \mathbf{C}\right)\end{array}$ & $\begin{array}{c}\mathbf{T}_{\mathbf{c}} \\
\left({ }^{\circ} \mathbf{C}\right)\end{array}$ & $\begin{array}{c}\mathbf{T}_{\mathbf{p}}-\mathbf{T}_{\mathbf{o}} \\
\left({ }^{\circ} \mathbf{C}\right)\end{array}$ & $\Delta \mathbf{H}_{\mathbf{d b}}(\mathbf{J} / \mathbf{g})$ \\
\hline Native & 0 & $66.6 \mathrm{a} \pm 1.4$ & $74.0 \mathrm{a} \pm 0.6$ & $77.3 \mathrm{a} \pm 5.2$ & $7.4 \mathrm{c} \pm 0.9$ & $2.819 \mathrm{a} \pm 0.778$ \\
& 0.5 & $67.3 \mathrm{a} \pm 2.1$ & $73.2 \mathrm{a} \pm 0.5$ & $78.3 \mathrm{a} \pm 0.5$ & $5.9 \mathrm{bc} \pm 1.6$ & $5.391 \mathrm{c} \pm 0.222$ \\
& 1 & $70.5 \mathrm{~b} \pm 1.4$ & $74.2 \mathrm{a} \pm 0.5$ & $78.4 \mathrm{a} \pm 0.4$ & $3.8 \mathrm{a} \pm 0.9$ & $4.132 \mathrm{~b} \pm 0.927$ \\
& 2 & $70.1 \mathrm{~b} \pm 1.0$ & $75.6 \mathrm{~b} \pm 0.9$ & $80.6 \mathrm{a} \pm 1.0$ & $5.5 \mathrm{~b} \pm 0.1$ & $4.014 \mathrm{~b} \pm 0.575$ \\
& 2 & $69.6 \mathrm{~b} \pm 1.2$ & $75.2 \mathrm{~b} \pm 0.4$ & $80.4 \mathrm{a} \pm 0.5$ & $5.5 \mathrm{~b} \pm 0.8$ & $5.645 \mathrm{c} \pm 0.148$
\end{tabular}

Values followed by the same letter in each column are not significantly different $(P<0.05)$. To, gelatinization onset; $\mathrm{Tp}$, peak temperature; Tc, conclusion temperature, Tp-To, gelatinization range, $\Delta \mathrm{H}_{\mathrm{db}}$, enthalpy, expressed as dry basis.

\section{Figure captions}

Fig. 1 - Environmental scanning electron microscope of maize flours. a, native; b, treated-0,5 min; c, treated-4 min. White and black arrows show disaggregated and aggregated structures, respectively.

Fig. 2 - X-ray diffraction patterns of microwaved flour samples as compared to native one. Arrow mark shows V-type structures. DSC patterns of the different times of treatment of flour (Native, 0.5, 1, 2 and 4 min) appear in vertical axis.

Fig. 3 - Pasting characteristics of maize flours. Viscosity profiles for Native ( - ) and microwave treated samples for $0.5 \min (\longleftarrow), 1 \min (-), 2 \min (--)$ and $4 \min \left(--\square^{-}\right)$are represented in vertical axis. Temperature profile is represented by 
Fig. 1

293
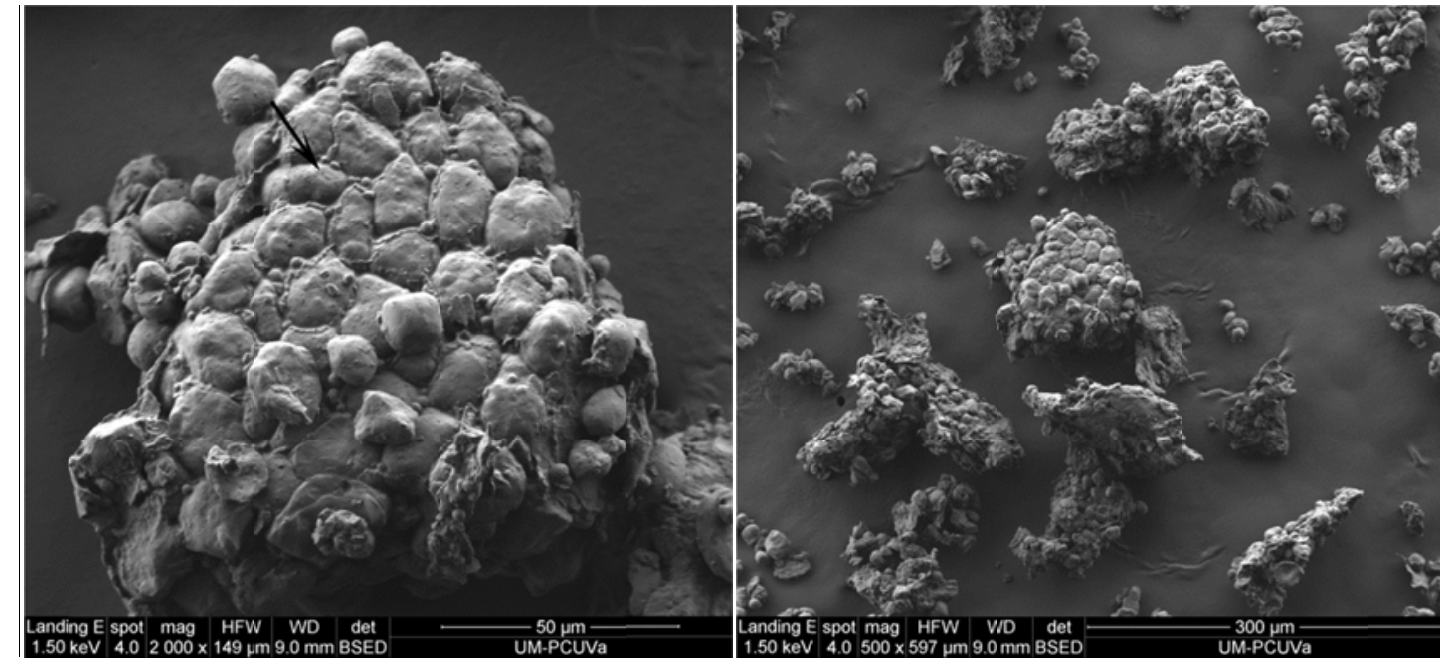

294

296

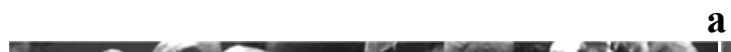

a

की

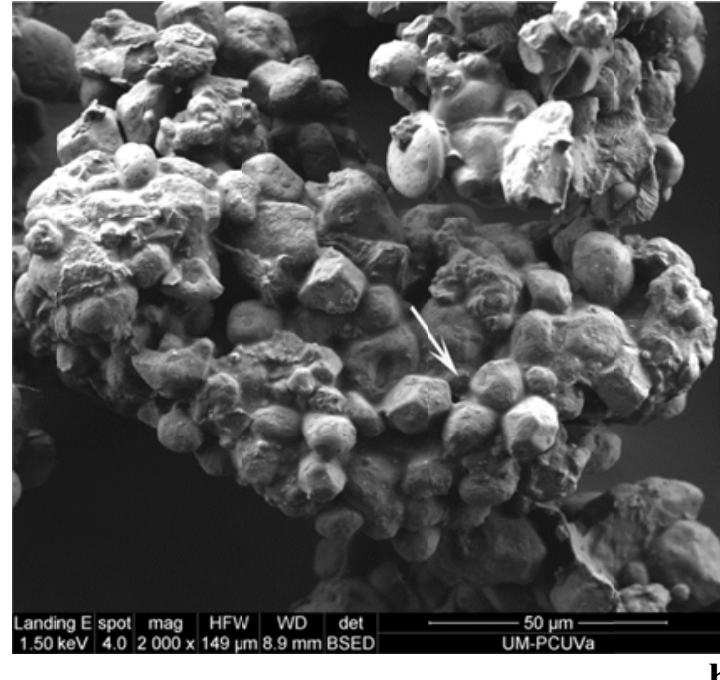

(2) 305

6. $\operatorname{arch}$

2.

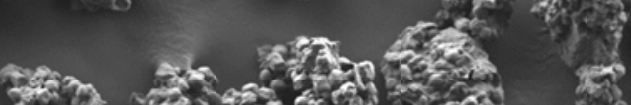

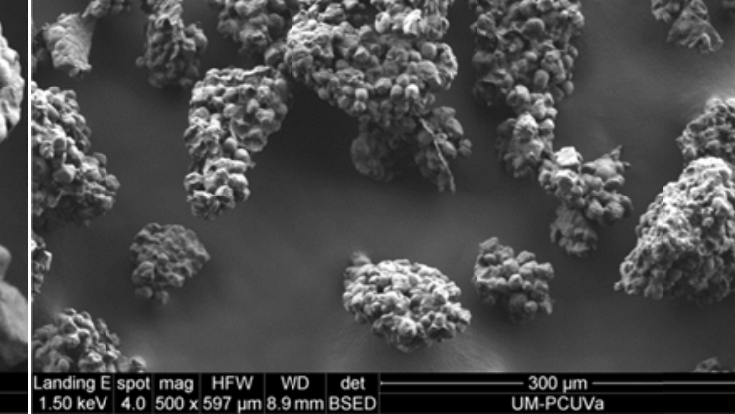

b

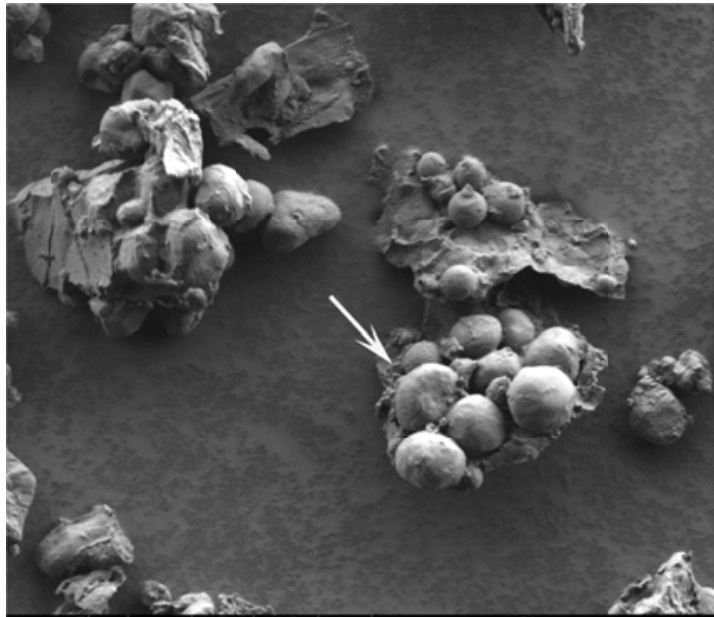


Fig. 2

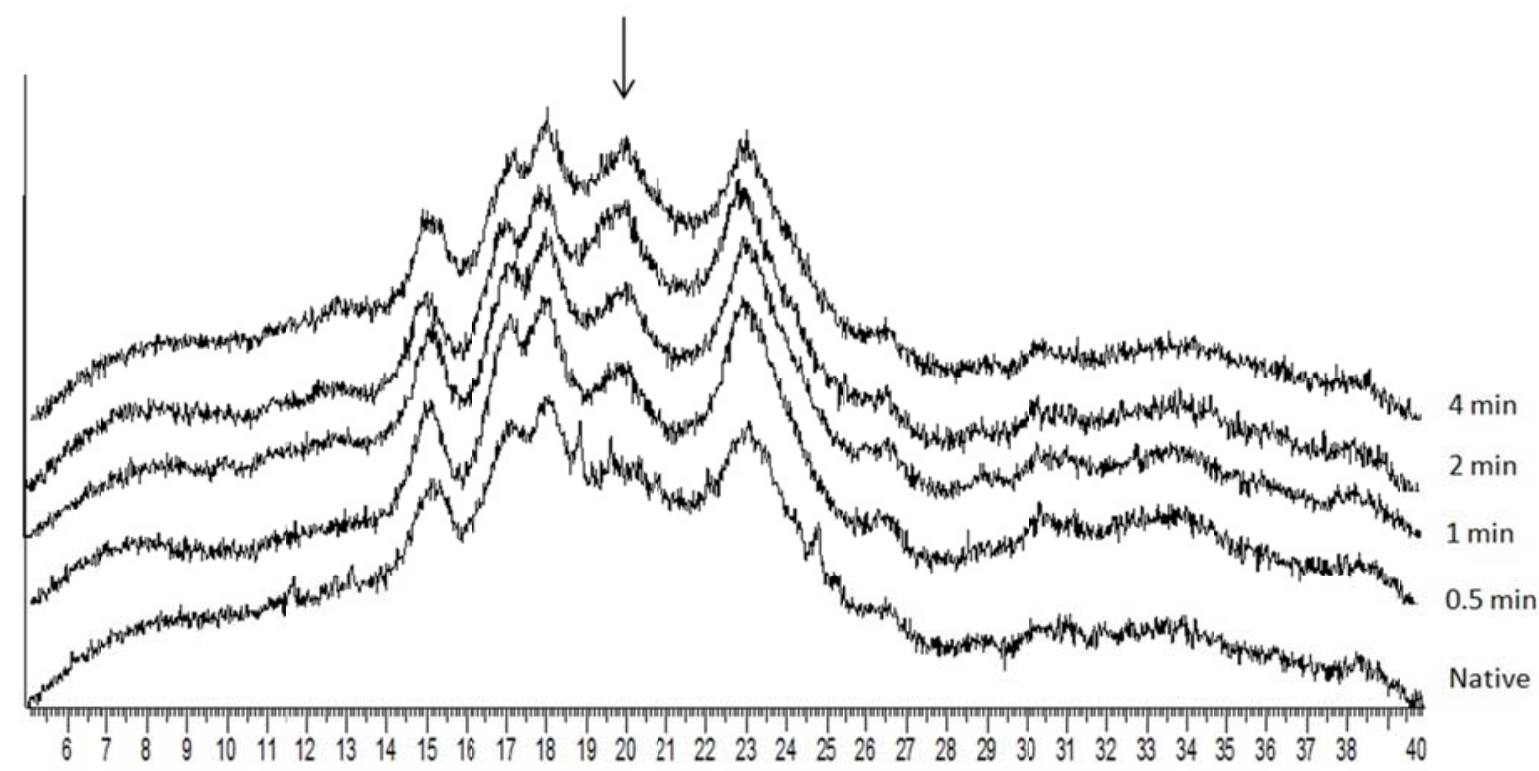

$301 \quad$ Fig. 3

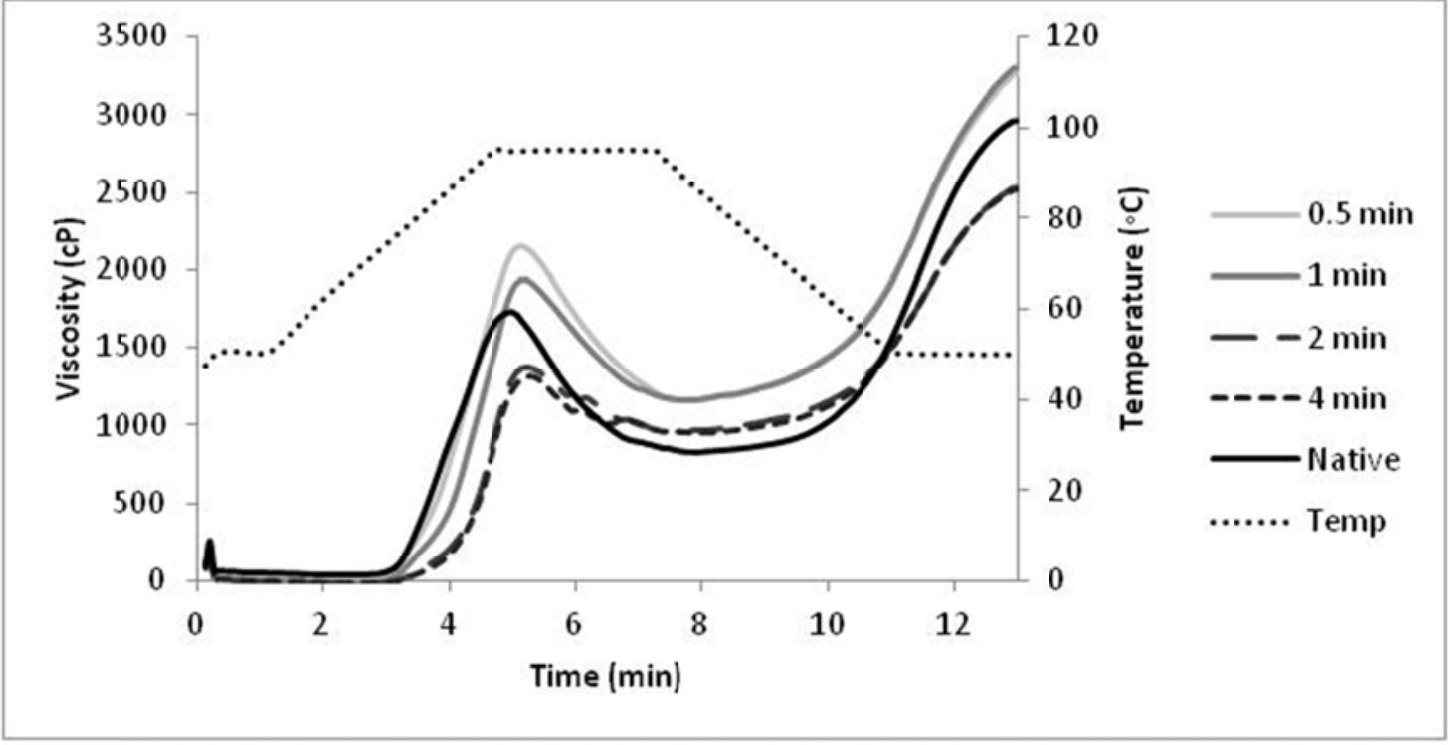

